\title{
"Snake": JURIDICIDADE, SOBERANIA E HOSPITALIDADE EM JACQUES DERRIDA
}

Gabriel Rezende de Souza Pinto

Mestrando em Direito pela Universidade de Brasília. Membro do Grupo do Estudos em Direito Internacional (GEDI) e do Flanar - Direito, Utopia e Democracia. Ex-bolsista de iniciação científica do CNPq

\begin{abstract}
RESUMO
D.H. Lawrence articula, no poema "Snake”, uma série de figuras ligadas ao pensamento político de Jacques Derrida. Este artigo argumenta que uma certa leitura cruzada entre essas duas extremidades poderia enxergar uma nova alegoria do Direito que, por sua vez, desestabilizaria as alegorias tradicionais do pensamento político-jurídico ocidental.
\end{abstract}

\section{PALAVRAS-CHAVE}

Soberania, desconstrução, juridicidade

\section{INTRODUÇÃO}

Proponho uma leitura do poema "Snake", de D.H. Lawrence. ${ }^{1}$ Em verdade - e para ser aqui mais justo tanto com os meus propósitos, quanto com os objetivos da II Jornada Jacques Derrida , evento realizado em 2010 pela Faculdade de Letras da UFMG - o que proponho é uma leitura, dentre as várias possíveis, da leitura feita por Jacques Derrida. Sem temor da repetição com efeito retórico, não seria menos importante dizer, por fim, que a leitura de Derrida, em si mesma, é também uma no interior de um vasto universo de leituras possíveis. Ou impossíveis.

O subtítulo deste trabalho parece comodamente explicativo: “juridicidade, soberania e hospitalidade em Jacques Derrida”. O recurso a uma listagem mais ou

\footnotetext{
${ }^{1}$ A versão consultada, que será citada durante todo o texto, é uma edição bilíngue presente em LAWRENCE. Poèmes. Ao longo do texto farei algumas citações do poema em sua versão original, ensaiando nas notas de rodapé traduções possíveis. Prezarei, nesse caso, pela manutenção do conteúdo, desprezando aqui o rigor poético.
} 
menos controlada, como essa, pode levar a crer que o texto que se segue dará igual atenção a todos esses termos. Tal impressão não deve ser mantida. Em verdade, estou interessado aqui em responder a uma pergunta muito específica: haveria, no poema de Lawrence, uma alegoria da normatividade jurídica que, a seu turno, desestabiliza o pensamento alegórico tradicional do Direito?

Soberania e hospitalidade servem-me aqui para a pequena cabotagem entre “Snake” e Derrida. Sem mapas hábeis a mostrar o caminho, só resta guiar-me por esses dois portos (nada) seguros retirados da obra do filósofo franco-argelino, os quais serão manejados com o intuito de responder adequadamente à pergunta formulada. A juridicidade, entretanto, não representa nenhum lugar de chegada ou, ainda, um zênite qualquer que opere efeitos reguladores. Pretendo argumentar em prol de um Direito que se justifique por sua abertura a uma democracia sempre por vir. Esse porvir não possui modelos, nem fórmulas. Não possui, sobretudo, tipos-ideais (Idealtypus) ${ }^{2}$ no que concerne à democracia participativa, à economia de mercado ou à sociedade civil figuras essas que adquiriram centralidade no raciocínio político contemporâneo.

Formulada de outro modo, a questão de que se ocupa este artigo nada mais é do que uma reflexão sobre o jurídico a partir da desconstrução da soberania ${ }^{3}$ e da hospitalidade sem condições. ${ }^{4}$

$\mathrm{Na}$ primeira parte do artigo, percorro as imagens principais do poema de Lawrence, fazendo referência às confluências de certas figuras com o pensamento de Jacques Derrida.

Em seguida, desenvolvo a via que julgo ser a mais proveitosa para os objetivos traçados. Para tanto, modulo a exposição em três tempos. Um primeiro bloco se volta contra o duplo risco de uma leitura dialética do poema. O segundo bloco lê "Snake" como alegoria desestabilizante das alegorias que compõem o discurso jurídico e prepara um terceiro bloco, dedicado à possibilidade impossível do Direito ou os direitos da amizade.

\section{O POEMA “SNAKE”}

\footnotetext{
${ }^{2}$ WEBER. Die Objektivität sozialwissenschaftlicher und sozialpolitischer Erkenntnis.

${ }^{3}$ Ver DERRIDA. Voyous - deux essais sur la raison; DERRIDA. Séminaire La bête et le souverain: volume I (2002-2002).

${ }^{4}$ Além dos textos citados na nota 2, ver também DERRIDA; DUFOURMANTELLE. Of hospitality.
} 
A cena em questão tem início com alguém, o Eu do poema, chegando à sua gamela, seu water trough. Munido de um jarro, esse Eu visualiza uma cobra que se instalara ali, gozando, por assim dizer, de sua hospitalidade. "Someone was before me at my water-trough”, escreve Lawrence. O verso traz o Outro que chegara antes, que viera antes. Ora, esse é o argumento primordial da desconstrução derridiana. A vivência da subjetividade como différance nos relembra, afinal, do rastro do Outro na composição da identidade do Eu. ${ }^{5}$ Daí por que Derrida sempre rejeitou as noções de “presença a si” vinculadas ao que se convencionou chamar de filosofia do sujeito. Sob a rubrica de hospitalidade, delimito a relação entre o Eu, homem, e o Outro, a cobra que forma o complexo maior da primeira parte do poema.

“Snake”, contudo, apresenta um segundo movimento - movimento, sim, pois não me arriscarei a dizer que haveria um segundo momento. É após o reconhecimento de si enquanto hospedador - como aquele que oferece sua hospitalidade - que surgem as vozes. O Eu passa a ser assombrado por vozes. E que vozes são essas? São as vozes de sua educação, as vozes de sua educação humana. Há aqui vozes que vociferam, que falam com raiva e, cheias de cólera, comandam o assassínio. Nós nos lembramos do quão preciosa é para Derrida a palavra vociferar e como ela representa um papel de extrema importância em sua caracterização do soberano a desconstruir.

“And voices in me said, If you were a man/ You would take a stick and break him now, and finish him off.”“. Se você fosse um homem”: aqui não apenas o homem como aquele portador de humanidade, mas o homem uirilis, o homem viril que se opõe à fraqueza da mulher. Vê-se, claramente, o quão conexas são essas imagens com o pensamento de Derrida. Ora, em maior ou menor medida, Lawrence coloca sobre a mesa uma série de temas que foram continuamente alvo de desconstruções: a humanidade do homem, o falogocentrismo, a mulher e a filosofia, a hantologia ${ }^{7}$ e os fantasmas e o vociferar. La bête et le souverain parece ser o exemplo mais claro de como Derrida lança mão de todas essas reflexões para discutir o espaço ocupado pela soberania no pensamento político e filosófico do Ocidente.

Aqui - e isto será importante mais adiante quando este texto se interrogar sobre

\footnotetext{
${ }^{5}$ CAPUTO; DERRIDA. La deconstrucción en una cáscara de nuez, p. 24.

6 "Vozes em mim disseram, se você fosse um homem, /pegaria um pau para machucá-lo e acabar com ele.” (LAWRENCE. Poèmes, [s. p.].) (tradução nossa)

7 DERRIDA. Spectres de Marx: L'État de la dette, le travail du deuil et la nouvelle internationale.
} 
as forças imaginantes do Direito e suas alegorias - é a voz humana, a voz do nómos, a voz que se inicia com o "Ne tueras point" , quem comanda a morte da cobra. Por que evitar dizer o homicídio da cobra? Afinal, é disso que se trata. A morte da cobra, comandada pela voz da educação humana, é a morte do personagem ao qual Lawrence se dirige utilizando o pronome masculino $H e$, e não o pronome it, coisificador, animalizante. Homo e caedo, com efeito, não estão muito distantes do propósito da cena.

Alternando a escala da análise, pode-se observar a substituição da hospitalidade, que dava a tonalidade afetiva do movimento anterior, por um discurso de segurança. A cobra passa a ser vista como o inimigo perigoso, posto ser "cobra dourada”, portanto, venenosa: "He must be killed,/ For in Sicily, the black, black snakes are innocent, the gold are venomous."8

Lawrence, nesse estágio, empreende uma descrição poética da hesitação do personagem. Se por um lado ele se sentia magnificamente honrado pela cobra, que era um alguém (someone), ele também se sentia preocupado com o acovardamento, o receio da pecha de fraco, de medroso. Finalmente, nessa tensão entre os dois sentimentos; entre a hospitalidade e a segurança, o personagem cede: toma um pedaço de pau e o atira contra a cobra, que já fugia por uma fenda do muro.

Após a tentativa de "homicídio", o poema adentra seu último movimento, o do arrependimento. Sem saber ao certo se havia ou não matado a cobra, o personagem se vê consternado com toda aquela situação: “And immediately I regretted it./ I thought how paltry, how vulgar, what a mean act!/I despised myself and the voices of my accursed human education." 9

Não há alternativa, senão a vivência do pesar. A fase do arrependimento alberga uma terceira relação com a cobra. O personagem, agora, reconhece nela uma dignidade inaudita: a cobra, para ele, parecia um rei. Um rei em exílio. O rei sem soberania ou, como prefiro entender, o rei de uma soberania outra, de uma soberania distinta, inconfundível: partilhável. O luto da cobra é o luto de um rei sem seu reino. Novamente, pontua-se uma série de imagens do pensamento de Derrida. Interessa-me a

\footnotetext{
"Ele precisa ser morto,/pois na Sicília, as negras, negras cobras são inocentes, enquanto as douradas são venenosas.” (LAWRENCE. Poèmes. Ver nota 1.) (tradução nossa)

9 "E imediatamente eu me arrependi./ Pensei: que ato mesquinho, vulgar, mau. Eu passei a menosprezar a mim e às vozes de minha maldita educação humana”. (LAWRENCE. Poèmes. Ver nota 1.) (tradução nossa)
} 
ligação entre soberania e animalidade. Nesse poema, o animal é o soberano, mas o é de uma forma diferente de um Leviatã, por exemplo. Quando Lawrence fala de soberania, ele já não está mais a falar da soberania de Hobbes e de Schmitt. Não mais aquela soberania que comandou, na forma de cânone, todo o pensamento político-jurídico da modernidade. Dessa soberania falarei mais adiante.

Em linhas gerais, esse é o poema.

\section{OS RISCOS DE UMA LEITURA DIALÉTICA OU DIALETIZANTE}

Antes de destrinchar, propriamente, o que compreendo serem os riscos de uma leitura dialética do poema de Lawrence, faço uma advertência. Não é minha intenção cobrar um ajuste histórico ou levar adiante qualquer crítica radical ao hegelianismo. Faltam-me mesmo as condições materiais de fazê-lo. Uma tentativa como essa só poderia conduzir este texto, na melhor das hipóteses, à superficialidade e, na pior, à falta de ética acadêmica.

Não por outra razão, preservo a obra maior de Hegel da análise que se seguirá. Ainda que seja meu objetivo recorrer ao argumento de que "Snake" não deve ser lido através do instrumental próprio da dialética, penso que minha intenção estará, num certo sentido, mais voltada à vulgata hegeliana e a seus discípulos.

Feito esse esclarecimento, desenvolvo agora a linha proposta.

Há dois riscos inerentes a uma leitura dialética do poema "Snake”. Quero evitar - e, novamente, é algo que ficará mais claro na sequência deste artigo - uma visão unificadora ou sintética na qual o último movimento do poema, aquele do arrependimento, figuraria como desdobramento final. Haveria, após um esforço dialético, duas interpretações possíveis desse poema. Na primeira delas, ver-se-ia o arrependimento como uma espécie de dialética interrompida. Não, contudo, para demonstrar a precariedade da razão, como o faz Walter Benjamin, ${ }^{10}$ mas para confirmála. Nesse sentido, haveria um caso falho da dialética do Senhor e do Escravo. ${ }^{11}$ Sem aprofundar uma discussão sobre essas implicações, retenho, simplesmente, a ideia de que há necessidade de pluralidade para o fiel desenvolvimento do Espírito (Geist). Sem

\footnotetext{
${ }^{10}$ Ver as teses sobre o conceito de história, traduzidas para o português em BENJAMIN. Magia e técnica, arte e política: ensaios sobre a literatura e historia da cultura.

${ }^{11}$ Para uma análise completa dessa alegoria que é, ademais, representativa do risco que sugiro, ver VAZ; TOLEDO; MOREIRA. Ética \& Direito, p. 183 et seq.
} 
multiplicidade não é possível o percurso no qual o Espírito toma consciência-de-si.

O poema de Lawrence poderia ser lido assim como uma dialética do senhor e do escravo interrompida, a qual confirmaria a insubstituível pluralidade, sem a qual só restará o arrependimento, um luto infinito desse Espírito que não pôde tomar consciência-de-si. Dito de outra forma, “Snake” seria apenas mais um recurso alegórico a demonstrar a necessidade lógica do movimento de revelação do Espírito na História. Essa conclusão é tudo o que pretendo evitar.

Outro risco da leitura dialética é o de ver a síntese como momento de transferência da soberania do Eu para o Outro. Mais distante do vocabulário e do horizonte hegeliano, essa preocupação remonta às críticas tradicionalmente dirigidas à desconstrução. Derrida chama a atenção para o risco desse tipo de interpretação de seu pensamento sobre a soberania. ${ }^{12}$ Desconstruir o soberano não significa, simplesmente, inverter as ordens de prioridade e hierarquias de um dado conjunto de relações. Ainda que esse seja um gesto importante para a desconstrução, ela a ele não se limita: é imperioso que, para além de toda inversão possível, subverta-se a lógica binária no sentido de embaralhar e desorganizar o sistema que faz o sistema. $^{13}$ Se não é compreendida dessa maneira, a desconstrução se reduz a uma troca de soberanos, uma usurpação.

Nesse particular, vê-se uma homologia entre as reflexões de Hannah Arendt sobre a Revolução Francesa ${ }^{14}$ e as de Jacques Derrida sobre a Ménagerie de Paris: ${ }^{15}$ não basta cortar a cabeça do rei se a soberania não for desconstruída. O resultado será, sempre, sua repetição sob outras formas, outras roupagens, por vezes mais sutis e mais perversas.

Derrida jamais propusera que o Outro fosse visto como soberano. Assim o seria, somente, caso se entendesse por soberano uma coisa outra, um mesmo nome para designar algo que já não mais se referia à Soberania tradicional, ou seja, aquela que ascendeu à condição de cânone no pensamento político ocidental: de Platão a Schmitt, passando por Hobbes.

É preciso evitar esses dois tipos de dialética para que se possa adentrar o

\footnotetext{
${ }^{12}$ DERRIDA. Séminaire la bête et le souverain: volume I (2002-2002). p. 371 et seq.

${ }^{13}$ Ver, nesse sentido, DERRIDA. Mémoires for Paul de Man.

${ }^{14}$ ARENDT. On revolution.

${ }^{15}$ DERRIDA. Séminaire la bête et le souverain: volume I (2002-2002).
} 
discurso derridiano. E é com ele que me dirijo ao segundo argumento deste artigo.

\section{AS ALEGORIAS DO DIREITO}

Como pensar o Direito aqui? Derrida jamais fora um filósofo do Direito - ao menos não um que tenha se preocupado com os aspectos mais relevantes de sua tecnicidade, como Habermas ou mesmo Ricœur, além de Villey e Dworkin. Todavia, é inegável que seu pensamento trouxe contribuições importantes para a disciplina, seja a partir do desenvolvimento dos Critical Legal Studies, seja a partir de sua própria obra. Afinal, Derrida ressaltou como a desconstrução encontra terreno fértil no Direito e como é preciso pensar uma Justiça indesconstrutível, a qual é ela mesma a descontrução. ${ }^{16}$

O problema do Direito surge em "Snake” mascarado sob diversas formas. Elejo, contudo, um caminho dentre os vários possíveis. Quero lê-lo como a possibilidade de uma alegoria desestabilizadora das alegorias que compõem o próprio Direito; uma alegoria do Direito pensado através da hospitalidade sem condições e da soberania de uma partilha impossível: um Direito impossível; uma democracia impossível; ambos sempre por vir.

Mas que alegoria é essa? Quão profundamente é necessário interrogar as tradições do pensamento ocidental para reconhecer o peso da $\alpha \lambda \lambda \eta \gamma o \rho i \alpha$ ? O que um pensamento sobre alegorias permite, finalmente, compreender sobre o Outro ( $\alpha \lambda \lambda \lambda \varsigma$ ) nele inscrito?

O Direito é lugar de importantes alegorias. Isto em razão de uma certa pergunta que o envolve e é a pergunta fundamental do político: qual o fundamento de legitimidade do Direito? Ou ainda: por que devemos respeitar as leis? É preciso repensar essas perguntas, e o próprio pensamento que as tornam possíveis: questionar infinitamente a teoria da política e do Direito fixada numa certa saudade da fundação ou uma nostalgia do soberano. O desenvolvimento da desconstrução do político em Derrida não é outro, senão um afastamento da genealogia do Nós, ou uma história da formação desta ou daquela comunidade, sem a qual não seria possível fundar a legitimidade do presente.

Derrida cruza duas perspectivas que me atiram a atenção.

\footnotetext{
${ }^{16}$ DERRIDA. Force de loi: le fondement mystique de l'autorité.
} 
De um lado, a proposta de um pluralismo ordenado em Mireille Delmas-Marty. ${ }^{17}$ As ideias dessa autora são preciosas não só para que se compreenda os novos lugares do universal e do relativo na teoria do Direito, mas também para que revele o double bind da soberania de que tanto fala Derrida.

Ora, se a crítica à soberania, aos seus limites, seus efeitos, seus pressupostos, suas consequências nefastas e excludentes, autoritárias e canônicas, parece cada vez mais urgente, é inegável também que sói utilizar-se desta mesma palavra para a definição do que é liberdade, libertação, emancipação. O desafio é pensar a desconstrução da soberania sem operar a destruição da liberdade. Ocorre, justamente, que é um novo pensamento da liberdade que emerge dessa desconstrução, sendo a um só tempo seu resultado e sua condição de possibilidade.

O double bind é que seria necessário ao mesmo tempo desconstruir, teoricamente e praticamente, uma certa onto-teologia política da soberania sem colocar em questão um certo pensamento da liberdade, em nome do qual se coloca a desconstrução em obra. ${ }^{18}$

Delmas-Marty e Derrida parecem dividir essa preocupação. A primeira tem defendido um pluralismo ordenado para fazer frente, por um lado, aos riscos de globalização de localismos ocidentais na esfera internacional, e por outro, aos riscos de distensão dos laços que ligam os Estados ao Direito. Universalismo e Relativismo, afinal, são apenas duas faces de uma mesma moeda que encerra o diálogo intercultural e previne um verdadeiro encontro em torno de direitos.

Em seguida, há a proposta do professor Marcelo Cattoni, ${ }^{19}$ o qual tem tentado desconstruir os discursos oficiais da historiografia da transição política brasileira. Para Cattoni, a deslegitimação da ordem democrática pós-88 passa pela nostalgia de um soberano uno e indivisível; um macrosujeito que poderia receber a denominação "povo" ou “nação”. É o pensamento canônico, afinal, que tem saudade deste messias, pois fora acostumado a pensar através de modelos fixos, prontos, prefabricados. Tudo que ocorra em dissonância com seu paradigma gera desconfianças insuportáveis que o

\footnotetext{
${ }^{17}$ DELMAS-MARTY. Les forces imaginantes du droit (II): le pluralism ordonné.

18،'Le double bind, c’est qu'il faudrait à la fois déconstruire, théoriquement et pratiquement, une certaine onto-théologie politique de la souveraineté sans remettre en cause une certaine pensée de la liberté au nom de laquelle on met cette déconstruction à l'œuvre.” (DERRIDA. Séminaire la bête et le souverain: volume I (2002-2002), p. 402.) (tradução nossa)

${ }^{19}$ CATTONI DE OLIVEIRA. Democracia sem espera e processo de constitucionalização: uma crítica aos discursos oficiais sobre a chamada "transição política brasileira".
} 
desestabilizam.

A teoria política brasileira ainda tem dificuldades em lidar com o projeto constituinte inaugurado em 1988. Por julgar ter existido uma transição concertada, na qual os militares negociaram sua saída do poder deixando ali uma elite que sempre houvera governado o país, parte dos teóricos têm colocado sob suspeita a existência de uma democracia em terra brasilis. O erro dessa perspectiva reside em desconsiderar que a democracia é sempre diferida no tempo, no sentido de ser uma democracia por vir. Cattoni e Derrida entendem, cada um a seu modo, que a legitimidade do Direito não se faz simplesmente em referência ao evento fundador da ordem política. Ao contrário dos adeptos do republicanismo, que instauram um regime de legitimidade por referência à fundação, a legitimidade está sempre por vir; ela não é jamais atual, não se materializa e não se presentifica; lança-se para o futuro por referência ao passado ao transformar memória em projeto.

Creio estarem as alegorias ligadas, tradicionalmente, a uma tensão entre as duas perspectivas que foram descritas. Entre a soberania e a legitimidade, a razão alegórica desempenha papel fundamental de justificação do poder e do saber do Direito.

Lawrence desestabiliza as alegorias da fundação. Coloca em xeque a perspectiva fundacional ao dizer que, desde sempre, alguém já estava bebendo da gamela; alguém sempre já estivera ali, antes de qualquer apropriação fundadora da sociedade, como quer Rousseau, ou mesmo antes de uma comunidade do mesmo, em Hegel (lembremos do papel da família no sistema hegeliano). Adiante, Lawrence coloca em descrédito o humano, o próprio do homem como fio condutor de um discurso societário: no lugar do “não matarás”, as vozes humanas ali dizem: “mate o outro!”

Lawrence permite, assim, um pensamento que vai além das alegorias fundadoras e se direciona a uma polemiologia originária (onde amigo e inimigo significariam uma mesma coisa). ${ }^{20}$ Ao inverso desse soberano uno e indivisível, que Derrida chama de um “poder-ver-fazer-ter”, Lawrence vê um soberano em exílio, um soberano sem coroa, ainda a vagar, como se seu reino fosse um reino futuro e sempre futuro, onde soberania já não significasse mais a mesma coisa. Julgo ser lícito pensar aqui algo parecido com a ideia de majestade em Celan: todos nós nos lembramos da transição que sofre esse termo, até alcançar a majestade da poesia, que nada mais tem que ver com a majestade do Rei Luís XVI.

\footnotetext{
${ }^{20}$ Ver DERRIDA. Politiques de l'amitié.
} 
Entre a hospitalidade sem condições e a soberania sem coroa da partilha, não se poderia pensar um Direito que se projeta para o futuro como prŏiectus? Não haveria ali uma nova alegoria mais apropriada à democracia por vir, e, por essa razão, desestabilizadora dos cânones jurídicos?

Entendo que a resposta é afirmativa.

\section{CONCLUSÃO: UM DIREITO (IM)POSSÍVEL}

Jacques Derrida é o pensador do impossível, daquilo que acontece, da acontecimentalidade (événementalité), daquilo que vem. Seu trabalho encoraja a deixar de lado a autoridade a priori dos cânones e investigar como o impossível e inesperado pôde e pode se tornar possível. No caso específico do Direito, essa discussão se desloca para a Justiça. Que justiça é essa que acontece e que é em si mesma a desconstrução, a possibilidade de desconstrução?

Aqui talvez valha a pena retomar brevemente alguns desenvolvimentos contidos em Politiques de l'amitié. O diálogo com Carl Schmitt parece levar Derrida a concluir que, de um modo muito específico, o juspublicista alemão estaria correto. Isso significa que Schmitt fora bem-sucedido, talvez como nenhum outro filósofo, em recolher as especificidades de uma longa tradição de pensamento do político e condensá-las. Tradição hegemônica, canônica, teológico-política.

Contudo, onde Schmitt parece ter acertado em seu diagnóstico se inicia a possibilidade de desconstrução dessa mesma tradição. Vê-se ali a possibilidade de encarar um sistema que baseou a teoria da política em cisões, mais especificamente no binômio amigo/inimigo, no mesmo e no outro, no cidadão e no estrangeiro e superá-lo, pensando justamente o que o sucede:

Se há uma tese no presente ensaio, ela sustentaria talvez que não haveria escolha: a decisão consistiria uma vez mais em optar sem excluir, em inventar outros nomes e outros conceitos, em se colocar para além dessa política aqui, sem cessar de nela intervir para transformá-la. ${ }^{21}$

Como pensar um Direito que se coadune com a exigência desconstrutiva de políticas da amizade? Há um Direito da amizade que lhe faça eco? Um Direito que

\footnotetext{
${ }^{21}$ “S’il y a une thèse au présent essai, elle poserait peut-être que choix Il ne saurait y avoir: la décision consisterait une fois encore à trancher sans exclure, à inventer d'autres noms et d'autres concepts, à se porter au-delà de ce politique-ci sans cesser d'y revenir pour le transformer.” (DERRIDA. Politiques de l'amitié, p. 183.) (tradução nossa)
} 
trabalhe a descontrução da fraternização (daquela fraternização) em nome de um fraternidade democrática do amigo, desse amigo por vir? Desse amigo que permite dizer “Ó meus amigos democratas...”? ${ }^{22}$

A tarefa de resposta a essa pergunta não me compete aqui. Ela precisa ser melhor trabalhada e melhor pensada. Sinais há de que coisa tal vem se desenvolvendo, sobretudo na ascendência de um direito internacional cosmopolita.

Contudo, o risco dos exemplos é muito grande. Prefiro encerrar o texto pensando apenas na abertura (im)possível possibilitada pelo poema de Lawrence e pela obra de Jacques Derrida.

\section{RESUMÉ}

D.H. Lawrence articule dans le poème "Snake” une chaîne de figures qui peuvent être liées à la pensée politique de Jacques Derrida. Ce texte-ci argumente que une certaine lecture croisée entre ces deux extrémités pourrait y voir une nouvelle allégorie du Droit qui, de son côté, bouleverserait les allégories de la tradition occidentale du politique et du juridique.

\section{MOTS-CLÉS}

Souveraineté, déconstruction, juridicité

\section{REFERENCIAS}

ARENDT, Hannah. On revolution. New York: Viking Press, 1963.

BENJAMIN, Walter. Magia e técnica, arte e politica:ensaios sobre a literatura e historia da cultura.7. ed. Trad. Sérgio P. Rouanet. São Paulo: Brasiliense, 1994.

CAPUTO, John; DERRIDA, Jacques. La deconstrucción en una cáscara de nuez. Trad. Gabriel Merlino Buenos Aires: Prometeo, 2009.

CATTONI DE OLIVEIRA, Marcelo Andrade. Democracia sem espera e processo de constitucionalização: uma crítica aos discursos oficiais sobre a chamada "transição política brasileira”. Revista Anistia Política e Justiça de Transição, Brasília, n. 3, p. 200-230, jan. 2010.

DELMAS-MARTY, Mireille. Les forces imaginantes du droit (II): le pluralism ordonné. Paris: Éditions du Seuil, 2006.

\footnotetext{
${ }^{22}$ DERRIDA. Politiques de l'amitié, p. 340.
} 
DERRIDA, Jacques. Force de loi: le fondement mystique de l'autorité. Paris: Galilée, 1994.

DERRIDA, Jacques. Mémoires for Paul de Man. New York: Columbia University Press, 1989.

DERRIDA, Jacques. Points de suspension. Entretiens. Paris: Galilée, 1992.

DERRIDA, Jacques. Politiques de l'amitié. Paris: Galilée, 1994.

DERRIDA, Jacques. Spectres De Marx: L'État De La Dette, Le Travail Du Deuil Et La Nouvelle Internationale. Paris: Galilée, 1993.

DERRIDA, Jacques. Voyous - deux essais sur la raison. Paris: Galilée, 2003.

DERRIDA, Jacques. Séminaire la bête et le souverain: volume I (2002-2002). Paris: Galilée, 2008.

DOUFOURMANTELLE, Anne; DERRIDA, Jacques. Of hospitality. Stanford: Stanford University Press, 2000.

LAWRENCE, D. H. Poèmes. Paris: Galimard, 1996.

VAZ, Henrique C. de Lima; TOLEDO, Cláudia; MOREIRA, Luíz. Ética \& direito. São Paulo: Landy: Loyola, 2002.

WEBER, Max. Die Objektivität sozialwissenschaftlicher und sozialpolitischer Erkenntnis. Tübingen: Wissenschaftlicher Verlag, Schutterwald, 1995. 